\title{
Pantomim di Indonesia: Sebuah Metode Pendidikan
}

Nur Iswantara ${ }^{1}$ dan Sunaryo

Prodi Pendidikan Seni Pertunjukan, Fakultas Seni Pertunjukan, Institut Seni Indonesia Yogyakarta
DANCé

jurnal tari, teater, dan wayang volume 2 number 1, May 2019 page $17-24$

\begin{abstract}
The learning methods of pantomime in Indonesia in the context of national education can be designed to support character education programs scheduled by the government through formal and non-formal education channels. The purpose of this study of pantomime learning methods is to package the way of parenting in the education realm. The method used is a qualitative method and method of action. The findings of the pantomime learning method are in the form of pantomime concepts and presentation techniques that offer new ways and procedures to improve and enhance the professionalism of the ability to educate pantomimes nationally. Thus in the presentation of pantomime learning with sign language, the expression on the face and body of the culprit can be appreciated by every person, community and citizen of Indonesia and other nations.
\end{abstract}

Keywords: pantomime; the professionalism of educators; character education; formal and non-formal education

\section{Pendahuluan}

Metode pantomim di Indonesia dalam perspektif pendidikan ini merupakan penemuan model pembelajaran seni pantomim untuk institusi pendidikan formal yang orientasi utamanya sebagai materi pendidikan bagi mahasiswa Program Studi (Prodi) Pendidikan Seni Pertunjukan, Fakultas Seni Pertunjukan (FSP) Institut Seni Indonesia (ISI) Yogyakarta. Selama ini pantomim diajarkan di sekolah-sekolah sebagai kegiatan ekstra kurikuler yang dikaitkan dengan seni drama/ teater. Bahkan seni pantomim tidak diajarkan sama sekali, karena kurangnya sumber daya manusia dan apresiasi terhadap seni pantomim di Indonesia.

Prodi Pendidikan Seni Pertunjukan FSP ISI Yogyakarta merupakan program pendidikan strata satu yang direncanakan dan direalisasi pada tahun ajaran 2014-2015. Sampai saat ini Prodi Pendidikan Seni Pertunjukan FSP ISI Yogyakarta memasuki tahun keempat dalam menyelenggarakan pendidikan. Ke- beradaan Program Studi S-1 Pendidikan Seni Pertunjukan adalah untuk merespons tingginya kebutuhan akan tenaga pendidik seni. Prodi S-1 Pendidikan Seni Pertunjuka ini berorientasi untuk menjawab kebutuhan tenaga pendidik seni sebagai salah satu pilar pembentukan karakter bangsa.

Profil lulusan Prodi S-1 Pendidikan Seni Pertunjukan memiliki orientasi untuk menjadi tenaga pendidik seni yang kreatif serta mampu memotivasi anak didik melalui proses belajar mengajar bidang seni berwawasan $\mathrm{Nu}-$ santara. Maka dari itu dasar dari pendidikan seni dalam Prodi S-1 Pendidikan Seni Pertunjukan ISI Yogyakarta berbasis pada konsep pendidikan integrated art, yaitu gabungan dari berbagai bidang seni (drama, tari, dan musik). Prodi S-1 Pendidikan Seni Pertunjukan ISI Yogyakarta tidak memfokuskan secara khusus pada ketrampilan satu bidang seni saja, tetapi mengembangkan esensi serta substansi masing-masing bidang seni untuk secara cerdas menjadi sumber inspirasi artistik dalam meningkatkan apresiasi dan kreasi karya seni.

1 Alamat korespondensi: Jurusan Pendidikan Seni Pertunjukan, Fakultas Seni Pertunjukan Institut Seni Indonesia Yogyakarta. E-mail: nuriswantara46@gmail.com; HP: 085100134636 
Program pembelajaran seni yang terintegrasi ini memiliki keunggulan dalam hasil pembelajarannya, yaitu: 1). Meningkatkan kemampuan akademik mahasiswa di bidang pendidikan seni; 2). Memperkaya pengetahuan dan kompetensi pendidikan seni yang terintegrasi dan multikultural; 3). Meningkatkan profesionalitas sebagai pendidik seni melalui pengalaman berkesenian; 4). Meningkatkan kemampuan untuk melakukan penelitian dan evaluasi pendidikan seni. Melalui keunggulan dalam pendidikan seni drama, tari, dan musik secara terintegrasi dan multikultural maka, mahasiswa mampu menjawab tantangan dalam berbagai permasalahan pendidikan seni di Indonesia. Lulusan Prodi S-1 Pendidikan Seni Pertunjukan ISI Yogyakarta diproyeksikan tersebar ke seluruh sekolah umum (SD-SMP-SMA) di setiap propinsi/kabupaten di Indonesia sebagai tenaga pendidik seni yang cerdas, kreatif, inovatif, serta mampu menanamkan nilainilai luhur karakter bangsa, melestarikan, dan mengembangkan aset seni budaya bangsa.

Pantomim sebagai sub pembelajaran dalam matakuliah Ekslorasi Peran pada Prodi S-1 Pendidikan Seni Pertunjukan ISI Yogyakarta kiranya perlu mendapatkan perhatian dalam metode pembelajarannya. Pantomim merupakan aset budaya bangsa Indonesia, berupa produk karya seni individu dan kolektif yang memiliki kandungan nilai seni (estetika), rekreasi (kegiatan tontonan dan hiburan), promosi (kegiatan propaganda dan penerangan), ekonomi (kegiatan pencaharian), dan edukasi (kegiatan pendidikan). Nilai seni (estetika) nampak dalam gerak-gerik aktor/seniman pantomim yang berekspresi melalui bahasa isyarat dengan tubuhnya. Nilai rekrerasi atau hiburan dapat dipresentasikan dengan kreasi-kreasi yang bersifat menghibur (menyenangkan), rasa nikmat dan rasa humor (membut ketawa).

Nilai promosi terungkap dalam ajakan atau tawaran terhadap produk-produk bangsa Indoensia yang bersifat moral dan material untuk dijadikan konsumen bagi penonton. Nilai ekonomi dapat dikemas sebagai media pergerakan ekonomi bagi pelaku seni pan- tomim (seniman), produksi dan penerbitan. Nilai pendidikan (edukasi) terungkap dalam pengajaran moral/watak/sifat/budi pekerti melalui cerita, tokoh, dan perilaku visual para seniman di area pertunjukan. Dengan Pantomim inilah mahasiswa dan masyarakat diharapkan mendapatkan apresiasi dan nilainilai pendidikan karakter.

Seni pantomim yang begitu komprehenship dalam makna dan fungsi tersebut kurang mendapatkan perhatian di kalangan generasi penerus yang berada dalam lingkup pendidikan (perguruan tinggi) secara nasional. Hal u dapat dipahami karena pantomim masih dalam format satu level yang orientasinya pada hayatan senimannya. Hal inilah yang menjadikan pantomim belum bisa menyentuh dunia pendidikan di Indonesia yang bersifat khusus dan berskala nasional.

Untuk itu, maka perlu diciptakan model metode pantomim dalam perspektif pendidikan tersendiri yang dapat dijadikan sebagai materi pendidikan karakter bagi anak bangsa Indonesia yang berbasis pada budaya sendiri. Di sisi lain, bangsa Indonesia sekarang ini mengalami dismoral, karena kehilangan jati diri yang bersumber pada nilainilai 'Kebinnekaan' yang bermakna beragam suku, agama, budaya, pendidikan, usia, jenis kelamin, dan sebagainya-- yang memuncak pada semboyan 'Tunggal Ika, yaitu menjadi satu tujuan, satu cita-cita, dan satu bangsa untuk bersatu padu dalam Negara Kesatuan Republik Indonesia (NKRI).

Pantomim yang ada sekarang ini masih bersifat monolevel, berorientasi pada hayatan senimannya dan fantasi orang dewasa yang mengutamakan nilai seni sehingga sulit diterima oleh lembaga pendidikan di Indonesia yang multi level (PAUD, SD, SMP, SMA, PT) dan multi etnis (Jawa, Sumatera, Kalimantan, Sulawesi, Bali, Madura, Nusa Tenggara Barat, Nusa Tenggara Timur dan Papua). Perancangan metode pantomim ini dapat diterapkan pada lembaga pendidikan nasional di negara kita Indonesia dengan harapan pada peningkatan nilai edukasi (pendidikan karakter/budi pekerti) dan menjunjung tinggi nilai-nilai kesatuan 
dan persatuan dalam kehidupa berbangsa dan bernegara melalui kajian seni budaya Indonesia khususnya pantomim. Dengan diterapkan pada dunia pendidikan formal, maka format pantomim diajarkan secara kognitif (pengetahuan/mengetahui), afektif (memahami/merasakan), dan psikomotorik (mampu melakukan/trampil).

Seni Pantomim memiliki nilai edukatif dalam rangka ikut serta membangun moral bangsa Indonesia yang sedang dirundung disbudaya dan dismoral. Dengan pantomim multi level dan multi etnis, bangsa Indonesia dapat memahami nilai-nilai kebinnekaan dan ketunggalikaan yang merupakan jatidiri bangsa Indonesia.

Pendidikan pantomim multilevel diharapkan dapat diajarkan secara nasional pada lembaga-lembaga pendidikan negeri maupun swasta mulai dari PAUD, SD, SMP, SMA, PT, sehingga nilai-nilai pendidikan melalui seni pantomim dapat diapresiasi oleh masyarakat di lingkungan lembaga pendidikan tingkat awal sampai akhir. Pendidikan pantomim multikultural dan nasionalis dapat dijadikan sebagai media apresiasi keberagaman dan kesatuan melalui seni budaya produk anak bangsa sendiri. Dengan pantomim dalam perspektif pendidikan inilah bangsa Indoensia dapat bersatu walaupun berbeda level dan etnisnya. Produk seni milik bangsa sendiri lebih mampu untuk mewujudkan cita-cita bangsa, karena sesuai dengan ideologi Pancasila

\section{Pantomim dalam Perspektif Pendidikan}

Semenjak penulis sekaligus peneliti bergabung dengan Gabungan Aktor Pantomim Yogyakarta (GAPY) pada tahun 1984 banyak bergelut langsung dengan dunia pantomim. Tampaknya pola gerak yang dijadikan dasar untuk membuat suatu karakter tertentu dalam pantomim belum sepenuhnya dipahami oleh para pelaku seni.

Berdasarkan fakta tentang keberadaan pantomim di Indonesia dapat diambil kejelasan sebagai berikut, Pertama, seni pertunjukan pantomim di Indonesia belum hadir sebagai ekspresi kesenian yang fungsional, ia masih sebatas sebagai wahana pencarian nilai artistik semata. Kedua, seni pertunjukan pantomim di Indonesia belum mampu mengundang tanggapan dan dialog yang berdaya guna dan berhasil guna dalam masyarakat. Ketiga, seni pertunjukan pantomim di Indonesia belum secara realitis menjadi cermin daya imajinasi yang beragam dari masyarakat serta belum mampu menampilkan diri agar dapat diterima secara universal. Keempat, seni pertunjukan pantomim di Indonesia dalam taraf proses menemukan jati diri di tengah gerak budaya yang semakin global. Setidaknya tampak pada setiap individu pantomimer berusaha menemukan bentuk kemasan pertunjukan, dan adanya kolektivitas seperti dalam GAPY seba gai wadah komunikasi sesama seniman mime guna menuju upaya profesionalisme bersama.

Buku Seni Pertunjukan Pantomim di Yogyakarta (Nur Iswantara, 1995) melacak jejak seni pertunjukan pantomim di wilayah Yogyakarta. Di Yogyakarta pantomim muncul sebagai seni pertunjukan sekitar tahun 1970an dengan perintisnya Moortri Poernomo yang mengajarkan gerak-indah, baik di ASDRAFI Yogyakarta maupun di sanggarsanggar. Jemek Supardi di tahun 1980 memulai karirnya sebagai pantomimer. Tahun 1981, Dedy Ratmoyo, mahasiswa ASDRAFI Yogyakarta, dengan arahan Moortri Poernomo melahirkan pantomim dengan judul Tukang Loak. Kemudian di tahun 1982, Jemek Supardi mementaskan Jemek Numpang Perahu Nuh di gedung Senisono Art Galery dengan penata musik Djadug Ferianto.

Di Yogyakarta, Jemek Supardi tahun 1986 mementaskan Lingkar-lingkar dan tahun 1987 mementaskan Kepyoh. Dedy Ratmoyo tahun 1986 mementaskan, Tambang, Pingpong, Skripsi, tahun 1988 mementaskan Dirigent, Ngintip, Pintu dan Pencuri. Pementasan pantomim dekade 1980-an memang sangat menggembirakan. Dekade 1980-an, eksistensi seni pertunjukan pantomim di Yogyakarta didominasi pementasan Deddy Ratmoyo dan Jemek Supardi. Deddy Ratmoyo giat berkarya pantomim, mengadakan lomba pantomim dan mengikuti lomba pantomim baik tingkat lokal maupun nasional serta dia juga pentas 
di hotel-hotel. Karyanya antara lain Rumah Sakit Jiwa. Ping Pong, dan lain-lain. Jemek Supardi aktif berpentas di gedung Senisono Art Galery, Taman Budaya Yogyakarta, dan hotel-hotel. Adapun karya Jemek Supardi yang patut disimak seperti Perahu Nuh, Adam dan Hawa. Dekade ini juga diramaikan oleh Djadug Ferianto, ia berpantomim di TVRI Stasiun Yogyakarta bersama-sama Jemek Supardi. Pantomim karya Djadug lebih banyak menggarap unsur musikalitas pertunjukan. Dekade 1980an yang penuh dengan kegiatan pertunjukan kontemporer, sehingga membuat pantomim ikut maju selangkah dalam penampilan.

Pantomim di Indonesia Seni Pertunjukan Yang Tumbuh Ekspresif (Nur Iswantara, 1998), menghasilkan pemahaman formatpertunjukan pantomim di Indonesia sebagai ekspresi seni. Di Jakarta dikenal kelompok Sena Didi Mime dengan seniman dan tokohnya Sena Utoyo dan Didi Petet. Karya-karya Sena Didi Mime antara lain Tong Sampah, Kampanye, Tukang Sapu Jalan, Jobles, Penari, Orang Buta, Petrus, Konsert. Martabak, Tarzan dan lain sebagainya. Kemudian di Yogyakarta dikenaili Gabungan Aktor Pantomim Yogyakarta (GAPY) dengan senimannya seperti Moortri Poernomo, Jemek Supardi, Deddy Ratmoyo, Faiq Ende Reza, Broto Wijayanto, Jamal El Triport dan lain sebagainya. Adapun karya-karya GAPY: Kelahiran (1993), Pilar Pilar 1994), Wajah Malioboro 1 (1995), Jailangkung (1996), Roro Mendut, Wajah Malioboro 2 (1998). Pantomim orientasinya untuk media ekspresi seniman dalam ranah kesenian di Indonesia.

Gerak Pantomim, Gerak Perkembangan: Dilihat Dari Dua Kota Indonesia (Nur Iswantara, 1999) berisi mencermati aktivitas pantomim di dua kota Jakarta dan Yogyakarta. Di Jakarta menurut Pramana Pmd., seorang pengamat mime, guru pada jurusan teater IKJ., menyatakan bahwa pantomim di Indonesia barasal dari tari dan akting dalam seni teater. Kapan pantomim di Indonesia lahir dalam kencah seni pertunjukan? Ungkap Pramana Pmd., Mime atau pantomime dua istilah yang hampir sama maknanya sedang dikembangkan oleh beberapa kalangan anak muda di negeri ini.
Jika amatan Pramana, Pmd. tersebut masih merupakan dugaan, dan itu terjadi di Jakarta, maka di Yogyakarta dugaan peneliti pantomim muncul dari gerak indah yang dikembangkan oleh Moortri Poernomo yang pernah belajar di Bengkel Teater itu. Terlepas antara ya dan tidak darimana sumber pantomim kita, sekiranya pantomim sebagai seni pertunjukan sudah sangat lama keberadaannya di dunia ini, Praman Pmd. Juga pernah menuliskan, bahwa pantomim di negeri ini dimulai oleh Sena A.Utoyo dan Didi Petet semenjak tahun 1977 di lingkungan IKJ.

Di Jakarta Septian dan kawan-kawan mengadakan Festival Pantomim Nasional yang diikuti oleh anak-anak muda sari segala pelosok tanah air. Hasil 5 dari 9 piala yang diperebutkan diboyong oleh kelompok Yogyakarta yang dipimpin Dedy Ratmoyo. Aktivitas pantomim di Indonesia pada dekade ini sangat merebak. Di Taman Ismail Marzuki Jakarta pada tanggal 10-11 April 1987, kelompok Sena Didi Mime mementaskan karya kolosal dengan judul Beca. Di cermati dari dua kota ini aktivitas pantomm di Indonesia berkembang menggembirakan. Akan tetapi belum dapat menjadi bagian penting dalam kehidupan seni di masyarakat dan lebih khusus dalam dunia pedidikan formal.

Wajah Pantomim Indonesia Dari Sena Didi Mime Hingga Gabungan Aktor Pantomim Yogyakarta (Nur Iswantara, 2007) menyajikan konsep memahami seni pantomim di Indonrsia yang mengulas tentang kontinuitas dan keberadaannya yang semakin ditinggalkan oleh para penggemarnya. Faktor utama yang menjadi penghambat dalam mempelajarinya yaitu dengan suatu metode yang tepat dan efisien sehingga dapat dipelajari oleh peserta didik dilembaga pendidikan formal dan khalayak umum..

Menyikapi konsep seni pantomim di Indonesia yang mengulas tentang kontinuitas dan keberadaannya yang kurang mendapat apresiasi masyarakat dan cenderung ditinggalkan oleh para penggemarnya. Faktor utama yang menjadi penghambat dalam mempelajarinya yaitu dengan suatu metode yang tepat dan efisien sehingga 
dapat dipelajari oleh peserta didik di lembaga pendidikan formal dan khalayak umum..

Program Studi Pendidikan Seni Pertunjukan FSP ISI Yogyakarta menyiapkan peserta didik/mahasiswanya akan menjadi guru wawasan seni budaya. Untuk itu dengan adanya metode pantomim dalam perspektif pendidikan akan dapat diajarkan di lembaga formal mulai dari Pendidikan Anak Usia Dini (PAUD), Sekolah Dasar (SD/MI), Sekolah Menengah Pertama (SMP/MTs.), Sekolah Menengah Atas (SMA/SMK/MAN). Kemudan juga dapat dipelajari oleh mahasiswa di Perguruan Tinggi (PT) dan masyarakat. Hal ini sebagai upaya kongkret pengembangan seni budaya pantomim di Indonesia dalam perspektif pendidikan.

\section{Pentingnya Metode Pembelajaran Pantomim}

Berdasarkan fakta tentang keberadaan pantomim di Indonesia dapat diambil kejelasan sebagai berikut:

Pertama, seni pertunjukan pantomim di Indonesia belum hadir sebagai ekspresi kesenian yang fungsional, ia masih sebatas sebagai wahana pencarian nilai artistik semata.

Kedua, seni pertunjukan pantomim di Indonesia belum mampu mengundang tanggapan dan dialog yang berdaya guna dan berhasil guna dalam masyarakat.

Ketiga, seni pertunjukan pantomim di Indonesia belum secara realitis menjadi cermin daya imajinasi yang beragam dari masyarakat serta belum mampu menampilkan diri agar dapat diterima secara universal.

Keempat, seni pertunjukan pantomim di Indonesia dalam taraf proses menemukan jati diri di tengah gerak budaya yang semakin global. Setidaknya tampak pada setiap individu pantomimer berusaha menemukan bentuk kemasan pertunjukan, dan adanya kolektivitas seperti dalam GAPY sebagai wadah komunikasi sesama seniman mim guna menuju upaya profesionalisme bersama.

Berdasarkan fakta dan eksistensi seni pertunjukan pantotomim sebagamana tersebut di atas dalam konteks pendidikan tampak 2 (dua) masalah, yakni: pertama, apresiasi seni pantomim yang menurun dan bersifat mono level, yakni lebih berorientasi senimannya atau seni orang dewasa sehingga kurang disosialisasikan ke dalam sistem pendidikan multi level. Kedua merosotnya akhlak anak bangsa Indonesia akibat perkembagan jaman. Ketidaksesuaian ini yang menimbulkan disapresiasi, karena merasa bukan dirinya atau bukan lingkungannya.

Dengan munculnya kedua masalah tersebut perlu diatasi dengan menciptakan metode pantomim sebagai sebuah perspektif pendidikan supaya semua lembaga pendidikan di Indonesia dapat mengapresiasi dan melaksanakan ajaran moral yang terkandung melalui seni pantomim.

Program Studi Seni Pertunjukan FSP ISI Yogyakarta menyiapkan peserta didik/ mahasiswanya yang akan menjadi guru wawasan seni budaya. Ruang lingkup pembelajaran seni budaya adalah empat bidang seni. Keempat bidang seni yang dimaksud adalah seni rupa, seni tari, seni musik dan seni drama (Budi Raharja, 2016:16). Pantomim pada Prodi S-1 Pendidikan Sendratasik ISI Yogyakarta sebagai subpembelajaran bidang Seni Drama masuk dalam matakuliah Ekslorasi Peran. Dengan demikian, diperlukan adanya metode pembelajaran Pantomim.

\section{Pembahasan}

Dalam menyusun metode pembelajaran pantomim dalam perspektif pendidikan penting untuk memahami konsep seniman pantomin Indonesia agar menjadi acuan penyusunan metode pembelajaran pantomim di Indonesia. Untuk itu konsep-konsep seniman pantomin Indonesia dipaparkan sebagai berikut.

a. Konsep Pantomim Seniman Pantomim Yogyakarta

1. Moortri Poernomo B.K.

Moortri Poernomo B.K. dalam proses kreatif mencipta pantomim dengan konsep sebagai berikut: 1). Ide, 2). Tema, 3). Penuangan ide, 4). Perwujudan (Nur Iswantara, 2007: 97-101). 


\section{Deddy Ratmoyo}

Deddy Ratmoyo dalam proses kreatif mencipta pantomim dengan konsep sebagai berikut: 1). Gerak tubuh, 2). Memori, 3). Ekspresi, 4). Emosi (Nur Iswantara, 2007: 111-114).

3. Jemek Supardi Jemek Supardi dalam proses kreatif mencipta pantomim dengan konsep sebagai berikut: 1). Menguasai olah tubuh, 2). Ide yang orisinal, 3). Keberanian berekspresi, 4). Pementasan (Nur Iswantara, 2007: 74-77).

b. Konsep Pantomim Seniman Pantomim Jakarta

1. Sena A. Utoyo

Sena A. Utoyo dalam proses kreatif mencipta pantomim dalam kelompoknya Sena Didi Mime dengan konsep sebagai berikut: 1). Akting/seniperan sebagai modal, 2). Dasar-dasar utama pembekalan dan pelatihan dasar,
3). Mengenal karakter, 4). Mengenal pro-perti, 5). Mengenal ide garapan, 6). Vokal, 7). Mngenal seni rupa, 8). Mengenal senmusik, 9). Pendekatan peran (Nur Iswantara, 2007: 51-55).

2. Didi Petet

Didi Petet dalam proses kreatif mencipta pantomim dalam kelompoknya Sena Didi Mime selalu kerjasama dengan Sena A. Utoyo. Akan tetapi Didi

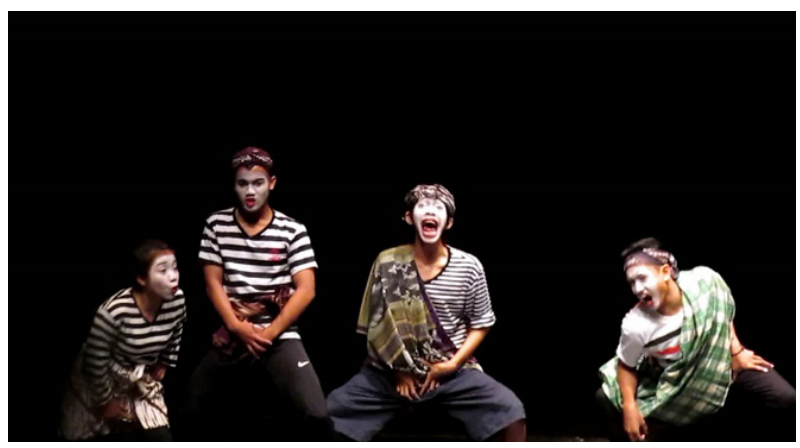

Gambar 1. DOKU-MIME 2018 di Concert Hall Taman Budaya Yogyakarta. (Sumber: Annisa NC Saputri/ Travelingyuk)
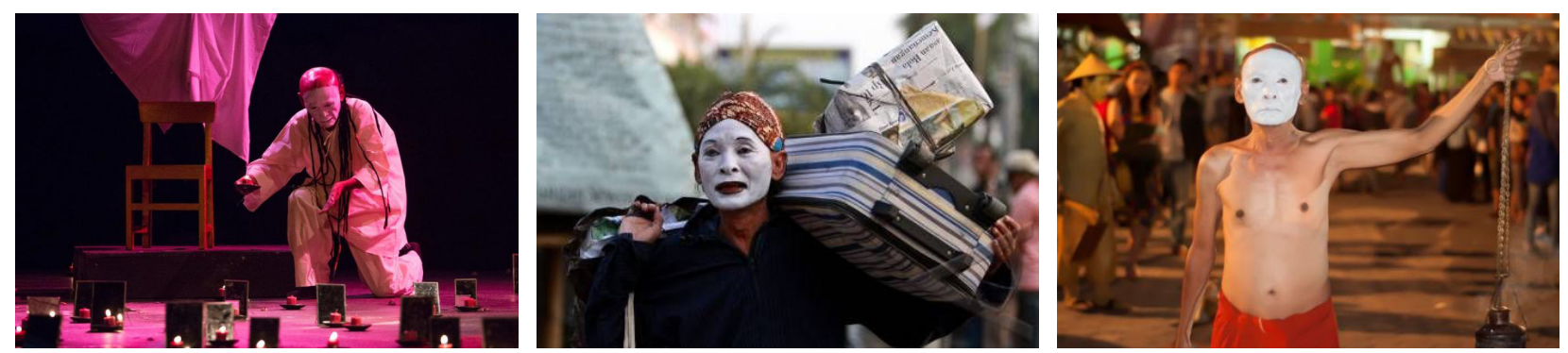

Gambar 2. Jemek Supardi. (Sumber: isigood.com)

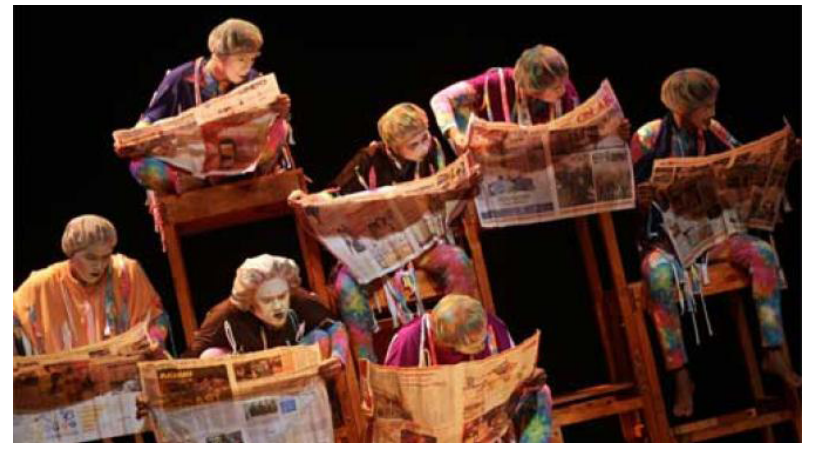

Gambar 3. Sena Didi Meme.

(Sumber: indopos.co.id)

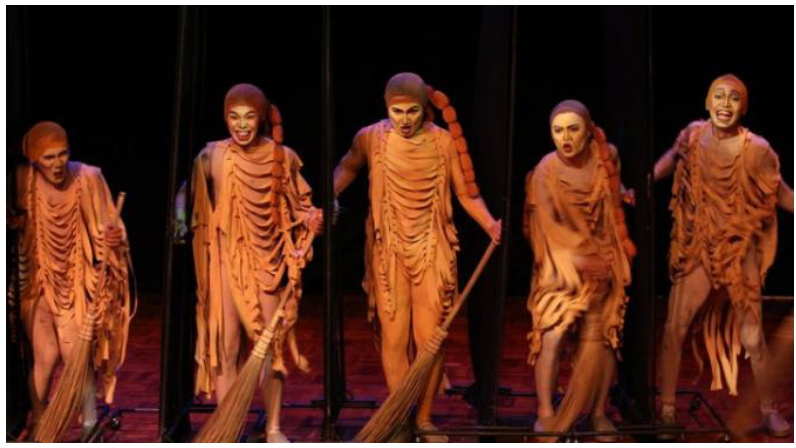

Gambar 4. Pertunjukan teater pantomim Sena Didi Meme. (Sumber: donypherwanto.wordpress.com)
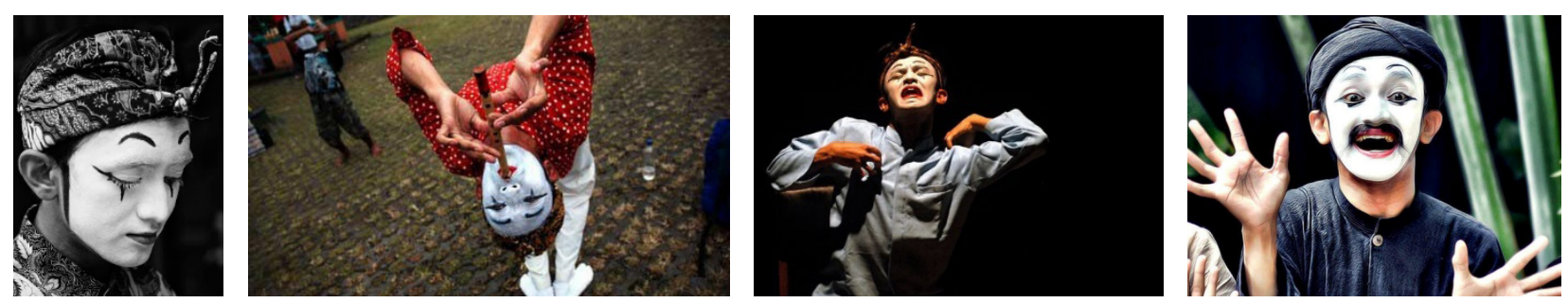

Gambar 5. Wanggi Hoediyanto. (Sumber: wanggihoediyanto.blogspot.com) 
Petet selaku sutradara memiliki konsep sebagai berikut: 1). Ide-ide kreatif, 2). Dasar pemikiran, 3). Konsep karya, 4). Casting pemeran, 5). Teknik latihan (Pemanasan, Konsentrasi, improvisasi), 6). Pementasan (Bekti Setyani Hartono, 2006: 40-69).

c. Konsep Pantomim Seniman Pantomim Bandung

1. Wanggi Hoediyanto

Seniman pantomim Bandung Wanggi Hoediyanto memiliki konsep sebagai berikut: 1). Ekspresi gerak indah tanpa kata-kata, gerak tubuh dan ekspresi wajah, 2). Menceritakan tentang fenomena dengan pengetahuan interdisipliner, 3). Mengangkat isu sosialbudaya masyarakat, 4). Diiringi irama musik ataupun tidak, 5). Bebas berimajinasi, 6). Berbagi senyuman, menghibur, keceriaan, therapist dan pengetahuan pada manusia.

Setelah memahami konsep-konsep seniman pantomim Indonesia dari tiga kota Yogyakarta, Jakarta dan Bandung maka dirumuskan konsep pantomim dalam rangka merancang metode pembelajaran pantomim di Indonesia. Dengan demikian pantomim Indonesia sebuah metode pendidikan pun memiliki model pembelajaran yang sistematis, terprogram dengan baik.

Metode pembelajaran pantomim dalam perspektif pendidikan memuat formulasi materi sebagai berikut: 1). Berimajinasi, 2). Membuat cerita, 3).Olah tubuh, 4) Bahasa tubuh dan bahasa isyarat, 5). Ekspresi, 6). Eksplorasi emosi dan perilaku, 7). Make-up dan kostum, 8). Musikalitas, 9). Tata rupa pentas, 10). Mencipta bentuk, 11). Pantomim meyakinkan, 12). Evaluasi. Formulasi materi tersebut akan disusun dalam Buku Ajar yang selanjutnya diujicobakan di Program Studi Seni Pertunjukan FSP ISI Yogyakarta.

\section{Penutup}

Dalam rangka mengatasi permasalahan menurunnya apresiasi masyarakat terhadap seni pantomim sebagai karya budaya bangsa sendiri dan merosotnya aklak anak bangsa Indonesia. Perlu metode pembelajaran seni pantomim dan nilai pendidikan untuk mengembangkan budaya sendiri sesuai perkembangan jaman dalam bentuk produk terapan metode pantomim di Indonesia dalam perspektif pendidikan.

Langkah yang perlu dilakukan adalah mencipta atau merancang metode pembelajaran pantomim multi level dengan menggunakan konsep pendidikan kognitif (pengetahuan/menjadi tahu), afektif (pemahaman/dapat merasakan), dan psikomotorik (ketrampilan/mampu melakasnakan). Proses penyusunan metode pembelajaran pantomim dengan memhami konsep pantomim seniman Indonesia yang kemudian dirumuskan menjadi formulasi materi pembelajaran pantomim secara sistematis dan terprogram.

Formulasi materi itu meliputi: 1). Berimajinasi, 2). Membuat cerita, 3). Olah tubuh, 4). Bahasa tubuh dan bahasa isyarat, 5). Ekspresi, 6). Eksplorasi emosi dan perilaku, 7). Make-up dan kostum, 8). Musikalitas, 9). Tata rupa pentas, 10). Mencipta bentuk, 11). Pantomim meyakinkan, 12). Evaluasi. Diharapkan metode pembelajaran pantomim memaparkan suatu upaya untuk memberikan pendidikan karakter/budi pekerti melalui seni pertunjukan pantomim di Indonesia sebagai langkah awal akan diujicobakan di Prodi S-1 Seni Pertunjukan FSP ISI Yogyakarta.

Metode pembelajaran pantomim untuk pendidikan dapat dijadikan sebagai model pembelajaran di lembaga pendidikan, mulai dari PAUD sampai Perguruan Tinggi di dalam mendidik karakter nasionalisme. Jiwa nasionalisme mrupakan nilai ideologis bagi bangsa Indonesia, sehingga akan menjadi bangsa yang kuat, damai, dan sejahtera lahir dan batin (menguatkan dan mensejahterakan). Di samping itu, dapat dijadikan sebagai media apresasi seni pantomim dan pengembangan budaya Indonesia.

Melalui metode pembelajaran pantomim untuk pendidikan secara nasional (mengapresiasi dan mengembangkan) bisa bermanfaat bagi bangsa dan negara Indonesia. 
Seni pertunjukan pantomim untuk pendidikan nasional dapat dijadikan sebagai promosi nilai nasionalisme, jatidiri bangsa dan negara Indonesia sehingga akan diapresiasi oleh setiap orang, masyarakat, warga bangsa Indonesia dan bangsa-bangsa dari negara-negara lain.

\section{Kepustakaan}

Aubert., Charles. 1970. The Art of Pantomim, New York: Benjamin,Inc.

Harymawan, RMA.1993. Dramaturgi,Bandung: Remaja Rosda Karya.

Iswantara. Nur. . 1999. “Gerak Pantomim, Gerak Perkembangan: Dilihat Dari Dua Kota Indonesia", Bandung: Laporan Penelitian Mandiri, Program Ekologi
Teater Indonesia (PETI) Masyarakat Seni Pertunjukan Indonesia (MSPI) Bandung. 2007. Wajah Pantomim Indonesia Dari Sena Didi Mime Hingga Gabungan Aktor Pantomim Yogyakarta, Yogyakarta: Media Kreatifa.

Pmd., Pramana. 1987. "Pantomim di Negeri ini". Dalam SKH Kompas, Jakarta:.

Raharja, Budi. 2016. Evaluasi Pembeljaran Seni, Konsep dan Aplikasinya untuk Evaluasi Hasil Pembelajaran Seni Budaya, Yogyakarta: Badan Penerbit ISI Yogyakarta.

Suroso. 2009. Penelitian Tindakan Kelas. Yogyakarta: Pararaton.

Suryabrata, Sumadi. 2004. Psikologi Pendidikan. Jakarta: PT. Raja Grafindo Persada. 